\title{
Presentación
}

\section{Dossier: La formación en dramaturgia en la historia reciente del teatro en Buenos Aires}

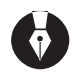

El presente Dossier presenta múltiples trabajos de integrantes del Proyecto FILO:CyT "La formación en dramaturgia: construcción de un campo de saberes específico en la historia del teatro argentino", radicado en el Instituto de Historia del Arte Argentino y Latinoamericano "Luis Ordaz". En sus dos años de trabajo, esta investigación, dirigida por Ezequiel Lozano y codirigida por Mariano Saba, ha acumulado una serie de elementos capaces de configurar cierto diseño provisorio del panorama en cuestión. Cabe explicar que las propuestas aquí publicadas obedecen al nexo aglutinante, a saber, estudiar los condicionamientos didácticos que, en el contexto de las últimas décadas, facilitaron la consolidación de una producción dramatúrgica nacional con amplia variedad y profusión de poéticas diversas. La valoración de la relevancia del elemento pedagógico en el plano de la escritura teatral no pretende excluir la incidencia que ha tenido en sus formas la existencia de un amplísimo abanico de elementos laterales que favoreció, sin dudas, la emergencia de un rango de prácticas distintas en torno a la dramaturgia nacional (desde la propia puesta en escena a sus cambiantes modos de producción, desde las contiendas intelectuales entre generaciones, a las distinciones intrínsecas de sus modalidades diversas, desde la transmisión de un oficio estabilizado al reacomodamiento incesante del campo dramatúrgico entre los años ‘' 90 y la actualidad).

Nuestra intención rectora pretende argumentar que, en las últimas cuatro décadas, la formación en dramaturgia cimentó la construcción de un campo de saberes específico en la historia del teatro argentino. Durante el extenso arco temporal que se evoca, también hemos intentado referir al proceso de institucionalización de la formación dramatúrgica reconociendo el carácter pionero de ciertas experiencias primarias hasta la relevancia de núcleos más tardíos (desde la Carrera de Dramaturgia de la Escuela Municipal de Arte Dramático hasta los módulos académicos posteriores que han tenido lugar en universidades diversas). De este modo, hemos buscado dimensionar el valor de los saberes dramatúrgicos, transmitidos tanto en talleres pioneros de "maestras" y "maestros" de la disciplina, como, también, en la proliferación de seminarios y cursos de las décadas más recientes. Hemos buscado, en este sentido, considerar siempre la gravitación del campo intelectual, y de la serie social y política, sobre los condicionamientos del ámbito particular estudiado, es decir, sobre la situación didáctica de la dramaturgia como saber técnico y estético puntual. En este tiempo de trabajo, el grupo ha podido exponer sus avances parciales impulsando múltiples actividades y entrevistas públicas ligadas al tema tanto en los últimos Festivales Internacionales de Buenos Aires, como también en congresos internacionales y jornadas especializadas. 
Estas instancias previas junto con el Dossier que aquí compartimos conforman un cuerpo de materiales cohesionado al cual lo guía una misma búsqueda de conocimiento que esperamos sea un aporte para la historia de nuestro teatro.

Dentro del espíritu de investigación que sigue alentando la cohesión del conjunto en torno al tema de la formación dramatúrgica, presentamos, específicamente en este Dossier, un espectro múltiple de los desarrollos de pesquisas de cada integrante. En su estudio, Ezequiel Lozano investiga el carácter pionero del Seminario para Autores de Argentores, creado en 1958 y sostenido -extensamente en el tiempo- por el dramaturgo Pablo Palant. Por su parte, el trabajo de Mariano Saba indaga en el contexto de la década de los ' 60 , momento en que la supuesta crisis de existencia del autor nacional parece haber sido -paradójicamente- condición de posibilidad para la aparición de seminarios y talleres de dramaturgia cuyo legado signaría a las décadas siguientes. Eugenio Schcolnicov, en su texto, investiga los procesos de enseñanza desarrollados por Ricardo Monti durante el gobierno de facto de la última dictadura militar, así como también las propuestas de taller que se llevaron adelante dentro del ciclo Teatro Abierto 1985. Ambas instancias habrían sido, en su opinión, eslabones significativos dentro del proceso de autonomización de los talleres posteriores de formación dramatúrgica. En el artículo de Carla Pessolano se desarrolla un relevamiento metaforológico (Blumenberg, 2003) de los discursos de espesor del grupo teatral Piel de Lava, para así dar cuenta del modo en que la formación en actuación y dramaturgia al comienzo de las carreras de sus integrantes implantó una forma de creación que influye hasta el día de hoy en sus procedimientos y en sus reflexiones acerca de los mismos. El trabajo de Sofía Elena Meza estudia la presencia de las mujeres dramaturgas en la escena porteña actual, focalizando en la formación dramatúrgica y en la producción destacada de Mariana "Cumbi" Bustinza. Además, invitamos para esta instancia de publicación al investigador Martín Rodríguez, quien elaboró un artículo que se propone describir los movimientos de una dramaturgia que parte del vínculo director/actor y excede los límites de la palabra sin excluirla.

Creemos que la suma de estudios sobre casos particulares relevantes para el campo permite brindar un panorama significativo acerca de la formación en dramaturgia en la historia reciente del teatro en Buenos Aires. Al mismo tiempo, consideramos que la paulatina pero incesante configuración de un registro amplio, aunque fragmentario, terminará por descifrar, con el tiempo, el territorio complejo y atomizado de la historia que nos guía: es decir, de esa historia arbórea -y poco conocida- que constituye la sucesión proliferante de núcleos donde ha ido teniendo lugar la enseñanza y el aprendizaje de la dramaturgia en Argentina. 